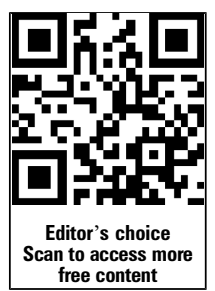

${ }^{1}$ Neonatal Intensive Care Unit, CHI Poissy Saint-Germain-enLaye, Poissy, France

${ }^{2}$ Neonatal Intensive Care Unit, Hôpital Antoine-Béclère, Clamart, France

${ }^{3}$ EA 7285, Université Versailles Saint-Quentin-en-Yvelines, Versailles, France

\section{Correspondence to} Professor Pascal Boileau Department of Neonatal Intensive Care Unit, CHI Poissy Saint-Germain-en-Laye, 10, rue du champ Gaillard, Poissy 78300, France; pboileau@chi-poissy-stgermain.fr

Received 4 March 2014 Revised 5 August 2014 Accepted 10 August 2014 Published Online First 28 August 2014

\title{
Natural evolution of patent ductus arteriosus in the extremely preterm infant
}

\author{
Audrey Rolland, ${ }^{1,2}$ Shivani Shankar-Aguilera, ${ }_{1}^{2}$ Douty Diomandé, ${ }^{2}$ \\ Véronique Zupan-Simunek, ${ }^{2}$ Pascal Boileau ${ }^{1,3}$
}

\section{ABSTRACT}

Objective The persistence of the patent ductus arteriosus (PDA) is frequently encountered in very preterm infants. Neither preventive nor curative treatments of PDA have been shown to improve the outcome of these infants. Since no consensus on optimal treatment of PDA is established, we evaluated the rate of spontaneous PDA closure in infants born before 28 weeks of gestation.

Patients and methods We studied a retrospective cohort of 103 infants (gestational age 24-27 weeks) admitted to our neonatal intensive care unit from 1 June 2008 to 31 July 2010. Maternal and neonatal characteristics were collected. The PDA was defined by the persistence of ductal patency after $72 \mathrm{~h}$ and was followed up by regular echocardiography.

Results Twelve infants died within the first $72 \mathrm{~h}$ and were excluded from the analysis. Among 91 infants analysed, 8 (9\%) closed their ductus arteriosus before $72 \mathrm{~h}$ and the ductus could not be determined patent in 13. Of the 70 infants with a PDA still persistent, one underwent surgical ligation and echocardiography showed spontaneous closure in 51 (73\%) of them. In the remaining 18 infants, the date of PDA closure could not be determined either because of their death $(n=11)$ or due to discharge $(n=7)$. Overall, a spontaneous closure of the ductus arteriosus was observed in 59 of the 91 infants.

Conclusions We have to question whether exposure to the risks of therapeutic interventions targeted for ductal closure is warranted since a PDA closes spontaneously in at least $73 \%$ of infants born before 28 weeks.

\section{INTRODUCTION}

The persistence of the patent ductus arteriosus (PDA) is frequent among preterm infants and its incidence is inversely proportionate to their gestational age at birth. Persistent PDA occurs in about two-thirds of extremely low-birth-weight infants, ${ }^{1}$ and $75 \%$ of those born before 28 weeks of gestation. ${ }^{2}$ Despite various randomised clinical trials conducted during the last three decades, there is no consensus on optimal treatment policy to achieve ductal closure in preterm infants. The efficiency of medical treatment by cyclooxygenase (COX) inhibitors (indomethacin, ibuprofen) on the closure of the PDA or on the resort to surgical ligation is well documented. ${ }^{3}$ Nevertheless, long-term benefits for the preterm infant other than those inherent to the treatment (ie, ductal closure or sparing surgical ductal ligation) remain uncertain and outcomes have not been shown to improve. ${ }^{4}$

\section{What is already known on this topic}

Medical treatments by cyclooxygenase inhibitors for patent ductus arteriosus (PDA) closure are routinely employed in neonatal intensive care units.

- Subsequent benefits of closing the PDA either medically or surgically in the preterm infant have not been demonstrated.

- In the extremely preterm infant, the natural history of the PDA has not been studied because of the early administration of treatments targeting its closure.

\section{What this study adds}

Without any specific treatment aimed to close PDA, a spontaneous closure rate of $73 \%$ was observed in infants born before 28 weeks of gestation.

- In the absence of evidence of improvements in outcome, exposure to the risks of therapeutic interventions targeted for ductal closure may not be warranted.

Two meta-analyses confirm that prophylactic treatment by indomethacin or ibuprofen before $24 \mathrm{~h}$ of life has no impact either on the mortality, incidence of bronchopulmonary dysplasia (BPD) or adverse neurodevelopmental outcomes up to 36 months. $^{5} 6$ However, indomethacin prophylaxis reduces the incidence of intraventricular haemorrhage (IVH) $\geq$ grade 3 by $30 \% 5$ and early serious pulmonary haemorrhage by $35 \% .^{7}$ The decrease in the incidence of severe IVH has not been demonstrated with the use of ibuprofen prophylaxis for ductal closure. ${ }^{6}$ No reported clinical trials to date were designed to compare prophylactic treatment versus no treatment. Administration of either indomethacin or ibuprofen after $24 \mathrm{~h}$ achieves ductal closure in a lesser number of cases but is not associated with a reduction in mortality or in shortterm outcomes such as BPD, severe IVH and necrotising enterocolitis (NEC) when compared with a placebo. ${ }^{8}$

In face of the risks associated with medical treatment and surgical ligation, some authors have questioned the benefits of treating the PDA either medically or surgically in the preterm infant. ${ }^{9}$ In 
clinical practice, treatment strategies vary from one neonatal intensive care unit (NICU) to another and several clinical teams have adopted a conservative or expectant treatment approach for the persistent patency of the ductus arteriosus. ${ }^{10}{ }^{11}$ In the absence of clear benefits of either preventive or curative treatment demonstrated on mortality and morbidity, we evaluated the rate of spontaneous closure of the PDA without any specific treatment aimed at its closure in infants born before 28 weeks of gestation.

\section{PATIENTS AND METHODS}

All infants born between $24^{0 / 7}$ and $27^{6 / 7}$ weeks of gestational age and admitted to the NICU at Antoine-Béclère Hospital from 1 June 2008 to 31 July 2010, either inborn or outborn, were retrospectively included. During this period, our standard approach to treatment of PDA was conservative. We did not use any COX inhibitor for prophylactic or after $24 \mathrm{~h}$ treatment of PDA; mechanical ventilatory parameters were adjusted with a low inspiratory time (Ti: $0.30-0.35 \mathrm{~s}$ ) and a high positive end expiratory pressure ( $\mathrm{PEEP}=5 \mathrm{mbar}$ ); fluid intake was limited to less than $140 \mathrm{~mL} / \mathrm{kg} /$ day beyond day 3 as much as possible.

Doppler echocardiography was performed with a GE Logiq 7 with a $10 \mathrm{MHz}$ transducer (General Electric Healthcare, Vélizy-Villacoublay, France) before day 4 of life. The PDA was defined by the persistence of ductal patency after $72 \mathrm{~h}$ of life with a left-to-right shunt. PDA was considered to be haemodynamically significant (HSPDA) on the echocardiography carried out between 3 and 4 days of life when internal ductal diameter was above $1.5 \mathrm{~mm}$ and there was increased pulmonary output documented by an end-diastolic flow velocity in the left pulmonary artery (LPA) measured by pulsed Doppler above $0.2 \mathrm{~m} / \mathrm{s}$ or a left-atrium-to-aortic-root (LA/Ao) ratio above $1.5 .^{12}$ All PDAs were followed up by regular echocardiography (once or twice a week), and when it showed the ductus to be closed, the date of the echocardiography was considered as the ductal closure date. The absence of spontaneous closure in a largesized PDA with increased pulmonary output (LA/Ao ratio above 1.8 and an end-diastolic LPA velocity above $0.2 \mathrm{~m} / \mathrm{s}$ ) in the context of severe respiratory failure was treated by a surgical ligation of the PDA.

For all infants included, we collected the following data:

- Maternal and perinatal characteristics including antenatal corticosteroid therapy, mode of delivery and the cause of preterm delivery (preeclampsia, chorioamnionitis, isolated premature rupture of membranes and isolated preterm labour).

- Neonatal characteristics: sex, birth weight and being small for gestational age defined by a birth weight below the 10th centile of the French standards (AUDIPOG). ${ }^{13}$

- Respiratory outcomes: number of exogenous surfactant doses administered, pulmonary haemorrhage, mechanical ventilation (through an endotracheal tube) and nasal intermittent positive pressure ventilation (IPPV) or continuous positive airway pressure (CPAP) duration before discharge. At 36 weeks postmenstrual age (PMA), the result of the Walsh test was used to define BPD. ${ }^{14}$

- Neurological outcome: the most severe grading of the IVH picked up by a cranial ultrasound scan (CUS) carried out in the first 15 days of life was recorded. We have used the classification of IVH as described by Volpe. ${ }^{15}$

- NEC and spontaneous intestinal perforation. In case of death, its cause was recorded.
- Duration of hospitalisation on NICU in days.

Data handling and statistical analysis were performed using the software 'Biostatgv' (Université Pierre-et-Marie-Curie, Paris, and Université Paul Sabatier, Toulouse, INSERM http://www. u707.jussieu.fr/biostatgv/). The comparative statistical analysis between groups was carried out by a non-parametric Fisher's test with a significant threshold of $<0.05$ for the $p$ value.

\section{RESULTS}

We identified 103 infants born between $24^{0 / 7}$ and $27^{6 / 7}$ weeks of gestational age, admitted to the NICU from 1 June 2008 to 31 June 2010. Twelve infants died in the first $72 \mathrm{~h}$ and were thus excluded. Three of them were born at 24 weeks, 6 at 25 weeks, 2 at 26 weeks and 1 at 27 weeks of gestation. The causes of death were four early-onset neonatal infections, two hypoxic respiratory failures non-responsive to inhaled nitric oxide, three pulmonary haemorrhages (two on day 1 and one on day 2 of life), one bilateral periventricular haemorrhagic infarction $(\mathrm{PVH})$ in the first $24 \mathrm{~h}$, one lung hypoplasia and one multiple congenital abnormalities.

Ninety-one preterm infants were analysed; their characteristics are listed in table 1 . The average maternal age was $30.6 \pm 5.4$ years, and the pregnancy was multiple in $21 \%$ of cases. A complete course of antenatal corticosteroid therapy was administered in two-thirds of cases. A single dose of betamethasone was received by $25 \%$ of women and in $10 \%$ of them there was no antenatal corticosteroid therapy. The prematurity was secondary to chorioamnionitis in $47 \%$ and to preeclampsia in $18 \%$ of cases, followed by isolated preterm labour in $24 \%$ and was related to isolated premature rupture of membranes in $9 \%$ of cases.

Exogenous surfactant was administered once to 55 infants $(60 \%)$, twice in 29 infants $(32 \%)$ and a third dose was given to 6 of them. Pulmonary haemorrhage was observed in $25 \%$ (23/91) of infants. The average length of mechanical ventilation and non-invasive respiratory support (nasal IPPV or CPAP) were of $26 \pm 19$ days (from 2 to 87 days) and $36 \pm 21$ days (from 3 to 168 days), respectively. At 36 weeks PMA, the rate of BPD was

Table 1 Perinatal and neonatal characteristics

\begin{tabular}{ll}
\hline Characteristic & Infants analysed ( $\mathrm{n}=\mathbf{9 1})$ \\
\hline Gestational age (weeks) & $26.3 \pm 1.0$ \\
Distribution of gestational ages & \\
{$\left[24^{1 / 7}-24^{6 / 7}\right]$ weeks, $\mathrm{n}(\%)$} & $11(12)$ \\
{$\left[25^{1 / 7}-25^{6 / 7}\right]$ weeks, $\mathrm{n}(\%)$} & $17(19)$ \\
{$\left[26^{0 / 7}-26^{6 / 7}\right]$ weeks, $\mathrm{n}(\%)$} & $36(39)$ \\
{$\left[27^{0 / 7}-27^{6 / 7}\right]$ weeks, $\mathrm{n}(\%)$} & $27(30)$ \\
Antenatal betamethasone (\%) & 66 \\
Vaginal delivery (\%) & 42 \\
Birth weight (g) & $823 \pm 164$ \\
Male (\%) & 59 \\
Small for gestational age (\%) & 20 \\
Exogenous surfactant $\geq 2$ doses (\%) & 39 \\
NEC (\%) & 3 \\
Spontaneous intestinal perforation (\%) & 2 \\
IVH $\geq$ grade 3 (\%) & 21 \\
BPD at 36 weeks PMA (\%) & 35 \\
Death (\%) & 17 \\
Death or BPD (\%) & 52 \\
\hline Data are presented as mean $\pm S D$ or $n(\%)$ or $\%$. & \\
BPD, bronchopulmonary dysplasia; IVH, intraventricular haemorrhage; NEC, \\
necrotising enterocolitis; PMA, postmenstrual age.
\end{tabular}


of $35 \%$. A CUS performed in the first two weeks of life found an IVH grade $\geq 3$ in 19 infants (21\%). No retinopathy of prematurity (ROP) was found before discharge.

The average admission days on the NICU were $73 \pm 34$ days (from 23 to 204 days). Fifteen infants died after $72 \mathrm{~h}$ of life. Five of them were born at 24 weeks, 4 at 25 weeks, 4 at 26 weeks and 2 at 27 weeks of gestation. The causes of death were one pulmonary haemorrhage, two hypoxic respiratory failures, one lung hypoplasia, two pneumothoraxes one of which was secondary to lung hypoplasia related to prolonged anamnios, one septic shock following nosocomial infection, three grade 3 IVHs with associated PVHs, two NECs, two multisystem failures and one oesophageal atresia. An ethical discussion among the medical staff and with the parents resulted in decisions of treatment withdrawal taken for four of these deaths (the three severe IVHs and the oesophageal atresia).

Of the 91 infants included, 8 (9\%) closed their ductus arteriosus spontaneously before $72 \mathrm{~h}$ of life and in 70 of them the PDA persisted beyond $72 \mathrm{~h}$ (figure 1). The infants in whom the ductal closure occurred before $72 \mathrm{~h}$ were born at an average gestational age of $27^{0 / 7}$ weeks \pm 5 days, whereas those with a persistent PDA were born at an average gestational age of $26^{2 / 7}$ weeks \pm 7 days. In 13 infants, the persistence of the PDA was not assessed by echocardiography after the first week of life. Three of them died at day 4, day 11 and day 12 of life, respectively. The remaining 10 infants were free of respiratory support at an average age of $7 \pm 6$ days (from 2 to 20 days), and none of them had a positive Walsh test at 36 weeks PMA.

Of the 70 infants with a PDA, echocardiography showed spontaneous closure in 51 infants $(73 \%)$ at an average age of $61 \pm 37$ days (from 4 to 165 days). Only one infant underwent surgical ligation of the PDA. In the remaining 18 infants, the date of PDA closure could not be determined either because of their death $(n=11)$ or because the echocardiography before discharge showed the PDA to be still persistent $(n=7)$. Three of them were later seen in follow-up, and the reviewing paediatrician found no heart murmur. The other four were transferred to another neonatal service before being discharged home. Overall, a spontaneous closure of the ductus arteriosus was confirmed by echocardiography in 59 of the 91 infants (65\%) and in 58 of the $76(76 \%)$ surviving infants.

Of the 28 infants born at 24-25 weeks, 25 (89\%) were found to have a PDA compared with 45 of $63(71 \%)$ infants born at

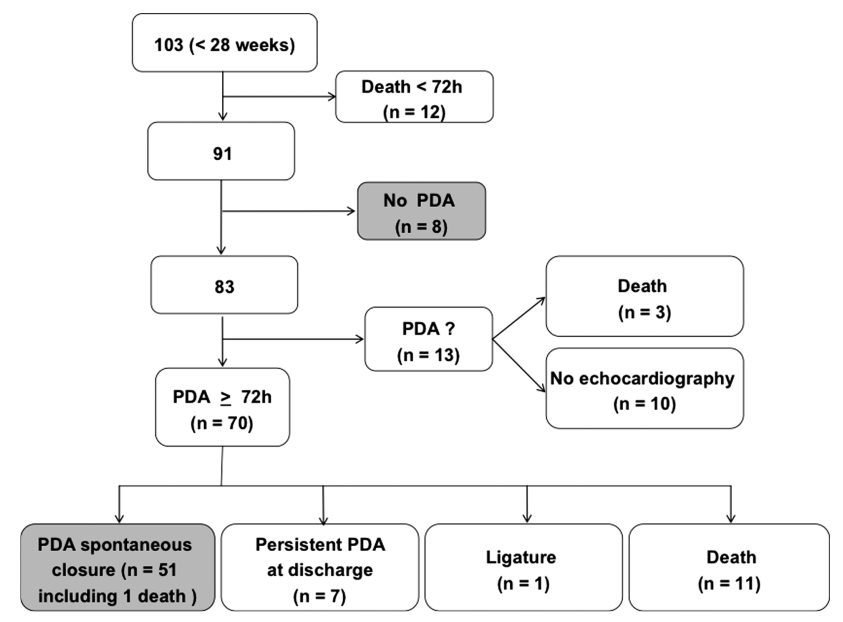

Figure 1 Natural evolution of patent ductus arteriosus in a population of infants born before 28 weeks of gestation.
Table 2 Evolution of persistent patent ductus arteriosus $(n=70)$ according to their haemodynamic characteristics at 3-4 days of life

\begin{tabular}{lccc}
\hline & $\begin{array}{l}\text { HNSPDA } \\
(\mathbf{n = 3 0 )}\end{array}$ & $\begin{array}{l}\text { HSPDA } \\
(\mathbf{n = 2 3 )}\end{array}$ & $\begin{array}{l}\text { IDHS } \\
(\mathbf{n}=17)\end{array}$ \\
\hline Spontaneous closure of the PDA, $\mathrm{n}(\%)$ & $22(73)$ & $18(78)$ & $11(65)$ \\
Death before discharge (PDA closure?), $\mathrm{n}(\%)$ & $4(13)$ & $2(9)$ & $5(29)$ \\
Survival at discharge (PDA closure?), $\mathrm{n}(\%)$ & $4(13)$ & $2(9)$ & $1(6)$ \\
Ligature of the PDA, $\mathrm{n}(\%)$ & 0 & $1(4)$ & 0 \\
\hline
\end{tabular}

HNSPDA, haemodynamically non-significant patent ductus arteriosus; HSPDA, haemodynamically significant patent ductus arteriosus; IDHS, insufficient data on haemodynamic status of the patent ductus arteriosus; PDA, patent ductus arteriosus.

26-27 weeks. The observed spontaneous PDA closure rate was $60 \%$ (15 of 25$)$ in infants born at 24-25 weeks compared with $80 \%$ (36 of 45 ) in those born at $26-27$ weeks. The rates of PDA occurrence or its spontaneous closure for infants born at 24-25 vs 26-27 weeks were not significantly different.

The evolution of a PDA towards spontaneous closure with regards to its haemodynamic significance as established by Doppler echocardiography is represented in table 2. In 17 cases, the documented data did not allow us to determine the haemodynamic status of the PDA. The spontaneous closure rate was observed in 78\% (18 of 23) of the infants with an HSPDA and in $73 \%$ (22 of 30 ) of those with a haemodynamically nonsignificant one. This difference was not statistically significant.

\section{DISCUSSION}

In the extremely preterm infant, the natural history of the PDA has not been studied because of the early administration of treatments targeting its closure. Among preterm infants, $70 \%$ of those born before 28 weeks of gestation receive either medical or surgical therapy for PDA closure. ${ }^{16}$ To justify the early use of these treatments on preterm infants in whom the PDA would possibly close spontaneously, the following two conditions seem necessary to us. First, it must be effective and its efficiency must be demonstrated not only on the closure of the PDA but also on mortality and long-term outcomes. Second, the clinical consequences of a persistent PDA must be more important than the risks undertaken by its treatment. The efficiency of medical treatment by COX inhibitors for PDA closure has been proved by numerous studies, but its efficacy depends on the age of the infant at the time of its administration. ${ }^{3} 17$ A prophylactic medical treatment in the first $24 \mathrm{~h}$ of life gives better results on ductal closure compared with a later treatment. In 257 infants born between 24 and 27 weeks, PDA closure was observed in $97 \%$ of infants treated before $15 \mathrm{~h}$ of life and in $51 \%$ of infants treated for an HSPDA at day 3 of life. ${ }^{2}$ In case of failure of medical treatment, a surgical intervention may be proposed. However, the surgical ligation has been described to possibly increase the risk of poor long-term outcomes in these extremely preterm infants. ${ }^{18}$ A recent study examined the effects of a 'conservative' approach towards a PDA persistent after one or two courses of indomethacin. In the group having systematically a surgical ligature of their PDA, the rate of NEC was higher than in the group operated on only in case of an HSPDA. ${ }^{19}$ For these different reasons, we have chosen a conservative attitude towards the PDA in treating it only if it has immediate deleterious clinical consequences.

In our study, we observed a spontaneous closure of the PDA in $73 \%$ of infants born before 28 weeks and a $9 \%$ early spontaneous closure rate defined as closure of ductus arteriosus 
before $72 \mathrm{~h}$ of life. Narayanan et $a l^{2}$ found a spontaneous ductal closure rate of $27 \%$ at day 4 in 143 infants born between 24 and 27 weeks. This last study described also a variable rate of spontaneous ductus closure according to the gestational age at birth with a rate of $31 \%$ among the infants born between 26 and 27 weeks and of $21 \%$ among those born between 24 and 25 weeks. Without limiting ourselves to the ductal closure during the first few days of life, our study did not show any significant difference in the spontaneous PDA closure rate between the infants born at 24-25 weeks and $26-27$ weeks $(60 \%$ vs $80 \%$ ). Finally, we did not observe the spontaneous PDA closure to be more frequent in infants with regards to the haemodynamic significance of the PDA (78\% vs 73\%).

In case of persistence of the PDA beyond the first few days of life, a later closure may occur. Herrman et $a l^{20}$ showed that $86 \%$ of very low-birth-weight infants with a PDA persistent at discharge spontaneously closed their PDAs at an average of 51 days of life. In our population of extremely preterm infants, we observed PDA closure at an average of 61 days of life with a large variation.

We cannot exclude that our conservative management of PDA may have resulted in an increased mortality. Four of the 12 deaths that occurred before the first $72 \mathrm{~h}$ were due to three severe pulmonary haemorrhages and one IVH-PVH, which could not have been prevented even with a prophylactic treatment of PDA. However, among the 15 deaths that occurred after $72 \mathrm{~h}$, one severe pulmonary haemorrhage and three severe IVH-PVHs could be related to the absence of very early treatment to close the PDA. The $17 \%$ rate of mortality observed in our population was higher than the $12 \%$ reported by Jhaveri et $a l^{19}$ in infants born before 28 weeks and treated by prophylactic indomethacin for ductal closure. For comparison with this last population, we have observed a higher rate of IVH grade $\geq 3$ (21\% vs $9 \%)$, a similar rate of BPD at 36 weeks PMA $(35 \%$ vs $32 \%)$, and a lower rate of NEC ( $3 \%$ vs $16 \%$ ) and ROP $\geq 2$ (0\% vs $14 \%)$.

\section{CONCLUSION}

Many therapeutic trials concerning the use of COX inhibitors used as either preventive or curative treatment of the PDA have been published in the last 30 years without any conclusion on either their short-term or long-term benefits. ${ }^{21} 22$ Currently, in the absence of tangible evidence regarding the efficiency of these treatments targeted for ductal closure on the mortality or short-term and long-term outcomes, we have to question these practices all the more so as a PDA closes spontaneously in at least $73 \%$ of infants born before 28 weeks of gestation.

Contributors Conception and design of the work: VZ-S and PB. Acquisition of data, analysis and interpretation of data: AR, SS-A, DD, VZ-S and PB. Drafting the article or revising it critically for important intellectual content: AR, SS-A, DD, VZ-S and PB. Agreement to be accountable for all aspects of the work in ensuring that questions related to the accuracy or integrity of any part of the work are appropriately investigated and resolved: AR, SS-A, DD, VZ-S and PB.

Competing interests None.

Provenance and peer review Not commissioned; externally peer reviewed.

\section{REFERENCES}

1 Koch J, Hensley G, Roy L, et al. Prevalence of spontaneous closure of the ductus arteriosus in neonates at a birth weight of 1000 grams or less. Pediatrics 2006;117:1113-21.

2 Narayanan $\mathrm{M}$, Cooper $\mathrm{B}$, Weiss $\mathrm{H}$, et al. Prophylactic indomethacin: factors determining permanent ductus arteriosus closure. J Pediatr 2000;136:330-7.

3 Johnston PG, Gillam-Krakauer M, Fuller MP, et al. Evidence-based use of indomethacin and ibuprofen in the neonatal intensive care. Clin Perinatol 2012;39:111-36.

4 Benitz WE. Patent ductus arteriosus: to treat or not to treat? Arch Dis Child Fetal Neonatal Ed 2012;97:F80-2.

5 Fowlie PW, Davis PG, Mc Guire W. Prophylactic intravenous indomethacin for preventing mortality and morbidity in preterm infants. Cochrane Database Syst Rev 2010;7:CD000174.

6 Shah SS, Ohlsson A. Ibuprofen for the prevention of patent ductus arteriosus in preterm and/or low birth weight infants. Cochrane Database Syst Rev 2011;7: CD004213.

7 Alfaleh K, Smyth JA, Roberts RS, et al. Prevention and 18-month outcomes of serious pulmonary haemorrhage in extremely low birth weight infants: results from the trial of indomethacin prophylaxis in preterms. Pediatrics 2008;121:e233-8.

8 Jones LJ, Craven PD, Attia J, et al. Network meta-analysis of indomethacin versus ibuprofen versus placebo for PDA in preterm infants. Arch Dis Child Fetal Neonatal Ed 2011;96:F45-52.

9 Bose CL, Laughon MM. Patent ductus arteriosus: lack of evidence for common treatments. Arch Dis Child Fetal Neonatal Ed 2007;92:F498-502.

10 Vanhaesebrouck S, Zonnenberg I, Vandervoort P, et al. Conservative treatment for patent ductus arteriosus in the preterm. Arch Dis Child Fetal Neonatal Ed 2007;92: F244-7.

11 Thankavel PP, Rosenfeld CR, Christie L, et al. Early echocardiographic prediction of ductal closure in neonates $\leq 30$ weeks gestation. J Perinatol 2013;33:45-51.

12 El Hajjar M, Vaksmann G, Razka T, et al. Severity of the ductal shunt: a comparison of different markers. Arch Dis Child Fetal Neonatal Ed 2005;90:F419-22.

13 Mamelle N, Munoz F, Grandjean H. [Fetal growth from the AUDIPOG study. I. Establishment of reference curves]. J Gynecol Obstet Biol Reprod (Paris) 1996;25:61-70.

14 Walsh MC, Wilson-Costello D, Zadell A, et al. Safety, reliability, and validity of a physiologic definition of bronchopumonary dysplasia. J Perinatol 2003;23:451-6.

15 Volpe JJ. Neurology of the newborn. 5th edn. Philadelphia, PA: Saunders, 2008:517-88.

16 Clyman RI. Ibuprofen and patent ductus arteriosus. N Engl J Med 2000;343:728-30.

17 Van Overmeire B, Smets K, Lecoutere D, et al. A comparison of ibuprofen and indomethacin for closure of patent ductus arteriosus. N Engl J Med 2000;343:674-81.

18 Madan JC, Kendrick D, Hagadorn Jl, et al. Patent ductus arteriosus therapy: impact on neonatal and 18-month outcome. Pediatrics 2009;123:674-81.

19 Jhaveri N, Moon-Grady A, Clyman RI. Early surgical ligation versus a conservative approach for management of patent ductus arteriosus that fails to close after indomethacin treatment. J Pediatr 2010;157:381-7.

20 Herrman K, Bose C, Lewis K, et al. Spontaneous closure of the patent ductus arteriosus in very low birth weight infants following discharge from the neonatal unit. Arch Dis Child Fetal Neonatal Ed 2009;94:F48-50.

21 Benitz WE. Treatment of persistent patent ductus arteriosus in preterm infants: time to accept the null hypothesis? J Perinatol 2010;30:241-52.

22 Smith LC, Kissack CM. Patent ductus arteriosus: time to grasp the nettle? Arch Dis Child Fetal Neonatal Ed 2013;98:F269-71. 